\title{
Changes in Investment Options in OECD Countries and Its Relationship with Analytical Tax Burden
}

\author{
Ahmet Niyazi Özker \\ Public Finance Department, Faculty of Economics and Administrative Sciences, Bandirma Onyedi Eylul University, Turkey
}

ORCID ID: 0000-0001-5313-246X

Received March 16, 2021; Revised April 6, 2021; Accepted May 23, 2021

\begin{abstract}
Cite This Paper in the following Citation Styles
(a): [1] Ahmet Niyazi Özker, "Changes in Investment Options in OECD Countries and Its Relationship with Analytical Tax Burden," Universal Journal of Accounting and Finance, Vol. 9, No. 3, pp. 295 - 305, 2021. DOI: 10.13189/ujaf.2021.090303.
\end{abstract}

(b): Ahmet Niyazi Özker (2021). Changes in Investment Options in OECD Countries and Its Relationship with Analytical Tax Burden. Universal Journal of Accounting and Finance, 9(3), 295 - 305. DOI: 10.13189/ujaf.2021.090303.

Copyright $@ 2021$ by authors, all rights reserved. Authors agree that this article remains permanently open access under the terms of the Creative Commons Attribution License 4.0 International License

\begin{abstract}
In this study, we aim to determine the extent to which the average investment limits affect the average tax burden under the OECD. It appears that international investment limits in OECD countries are affected by three components. Undoubtedly, one of these is the average tax burden under the OECD. Other components are the average debt ratios of governments and countries' real growth movements on economic growth, which affect the global average measure of investment services. It is observed that the changes in investment options in OECD countries show significant differences according to the average tax burdens of the countries and affect the investment limits significantly. This phenomenon put forth a significant change effect on investments as an average of criteria effect, and this approach makes it meaningful to conduct a tax burden-based study. Since the tax burden phenomenon in countries varies in terms of domestic and foreign debt of countries and is directly related to growth rates. The fact that changes in the average tax burden of OECD member countries affect investments reveals that it is dependent on the tax burden, the GDP of the relevant countries and the average debt burden of the OECD countries. Domestic and public foreign debt options of these countries directly affect the OECD's average investments. It shows that this influence analytically increases the negative criteria based on investments in these countries concerned.
\end{abstract}

Keywords Debt Ratios, Gross Domestic Product (GDP), Growth Rates, OECD, Tax Burden
JEL Codes F21, F62, F63.

\section{Introduction}

The scope of international investments refers to the economic values where investment profiles shaped in different geographical regions are realized with fiscal and financial investment instruments globally [1]. Increasing the diversity of investments and presenting possible investment risks in global markets under certain risk standards are characteristics of international investments. International investments mean savings on securities issued by companies or governments, especially in OECD countries, and an approach that also means international investments globally vary at different levels with the scale of impact of countries' macro values [2]. Therefore, it appears that international investments continue within the scope of having foreign assets, being affected by changes in foreign exchange rates, the level of impact of changes in global interest rates, and possible risks arising from geopolitical events. Potentially, some important impact scales for global expansion affect some systematic risks [3], which directly relates to the financial balance, economic growth of the countries, and the investment portfolios [4]. Another issue that should be emphasized in our study is that this study, which aims to analyses the effect of the tax burden on investments, is handled in a completely different 
approach from today's tax wedge and investments related study. It includes different components [5]. Since the tax wedge phenomenon includes values such as labour cost in production and cost elements in the production process such as insurance premiums, in this study, the average investment variability within the scope of the OECD is directly associated with the empirical analyses framework of the tax burden [6].

The ability of OECD level investors and OECD member countries to transform these investment portfolios into international investment options is based on the principle of realization by offering investment funds with different financial values [7]. On the other hand, these investments also mean investments with different options on currencies and are realized with futures transactions at the global level. The use of different currencies and different growth standards in OECD countries constitutes an important holistic structure that directly affects the variability in OECD countries' investment limits at the international level. However, it reveals that the primary purpose at the level of targeted investments for OECD countries is to make investments directly affected by the tax burden [8]. In other words, in this process, the variability of the investments made within the countries' tax burdens creates a significant scale effect in a global investment variability. One of the critical factors on which investment volatility in OECD countries has been undoubtedly dependent on the GDP ratio changes [9]. At this stage, GDP changes associated with production growth limits also give average investment changes with new production levels. At this stage, the production-related correlations are essential for OECD countries and represent changes in average investment. Regardless of the location, it is seen that the amount of government debt in the process and interest rates also constitute an important correlation for investment variables. In addition to government debt, it appears that the variability investments in the OECD in their relationship with the tax burden shows a significant correlation due to tax burdens. In other words, there is a considerable effect level that the variability in investments directly affected by the changes in tax. In this respect, the effect of the changes in the tax burden positions in the OECD as the average tax burden on investments is indisputably important, and there is another level of global impact directly related to the increase in the tax burden. Undoubtedly, due to the direct relationship between government borrowing changes and the differences in production output with the tax burden, a significant level of influence on investment limits also emerges at this stage [10].

\section{Literature Review}

One of the important studies on the subject within the scope of OECD is the study conducted by the OECD [11], which is a short self-study. The study was conducted in
2008, aiming to examine the tax effect on foreign direct investments as the summary and it tried to determine the effects of corporate tax and changes in effective tax rates. Again, another critical study on investments within the OECD's scope in this regard is the study conducted by Torres [12]. In this study, an analytical analysis of the relationships between taxes and investments has been made. In this study, we see that the effect of tax incentives on investments theoretically discussed in this process. In this study, essential determinations regarding the measurement of the tax effect on investments are included. However, one of the most up-to-date studies based on investments in OECD is the study conducted by Alves [13]. In the study, the relationship between tax burden and investments has been analyzed using an econometric method. This study, especially the OECD countries' structural change methods for investments, examined and changed phenomena regarding investments evaluated as the OECD countries' average. The study is still up-to-date as an important empirical study in which the effect of the tax burden on investments is discussed together with other tax practices. Again, in this context, the study conducted by Enache [14] is critical research within the OECD's scope, which concerns investments indirectly and considers investment costs. This study, which considers the investment costs of the assets within the OECD's content, has revealed meaningful results. Other factors besides the fiscal factors affecting the investments are also taken into consideration, and the relationship with the tax burden is questioned [15].

\section{Dynamics of Investment Variability and the Influence Position of Fiscal Balances in the OECD}

Undoubtedly, government debt, which affects investment volatility, is one of the most critical OECD investment dynamics. Besides, changes in the output values of investments and the effect of interest rates on investments constitute a fundamental influence level [16]. Changes in the average growth rates of countries in the OECD constitute an important issue that directly affects indirect investments. However, as a factor affecting investments, it provides advance information about investments, especially in financial markets, collects savings and allocates them to investments also constitute essential investment variability [17]. Facilitating the purchase and sale of financial assets related to the tracking of investments and the trading of goods and services for diversification of investment portfolios are also important dynamics affecting investment variability. In this context, the effect of the tax burden phenomenon as a variable of investments within the scope of OECD on investments is seen. Therefore, the effect level of changes in government debts structurally is high as investment dynamics. However, 
it appears that it is inevitable that the changes in interest rates will create a significant variability. On the other hand, exports are negatively affected due to increases in national income and household consumption, and the increase in import directly affects investments as fiscal values [18]. It would not be a mistake to say that investment volatility in the sectors changes profitability in this context. Competitive sectors also reveal a mechanism directly related to an effective tax burden. The tax burden phenomenon is an important cost element for target investments in production and sectors [19].

It is observed that the effect of the tax burden is an important cost factor, which expresses which part of the income can be taxed, especially by affecting government debts and increasing interest rates in countries parallel to this [20]. In the same period, it appears that the requirement for public finance increased, which cause an effect on the tax volatility increased, as an important cost factor on sectors and investment limits, significantly in the years when government debts increased. In OECD countries, this variability directly has affected the countries' investment limits; on the other hand, it negatively affects the current account balance and foreign trade relations directly related to investments [21]. In an environment where government debt declines, it is seen that the ratio of increases in interest rates to GDP also decreases with a mutually inverse relationship. In other words, as public financing requirements increase, domestic interest rates increase, leading to an increase in tax burden on investments. This process, which negatively impacts investments with the increasing tax changes regarding the public financing need, also exerts a significant divergence effect on the OECD average investments. In the Figure 1 below, it is possible to trace the change in government debt, average rates for investments, and the relationship of changes in interest rates on investments with the GDP within the OECD countries' scope [22]:
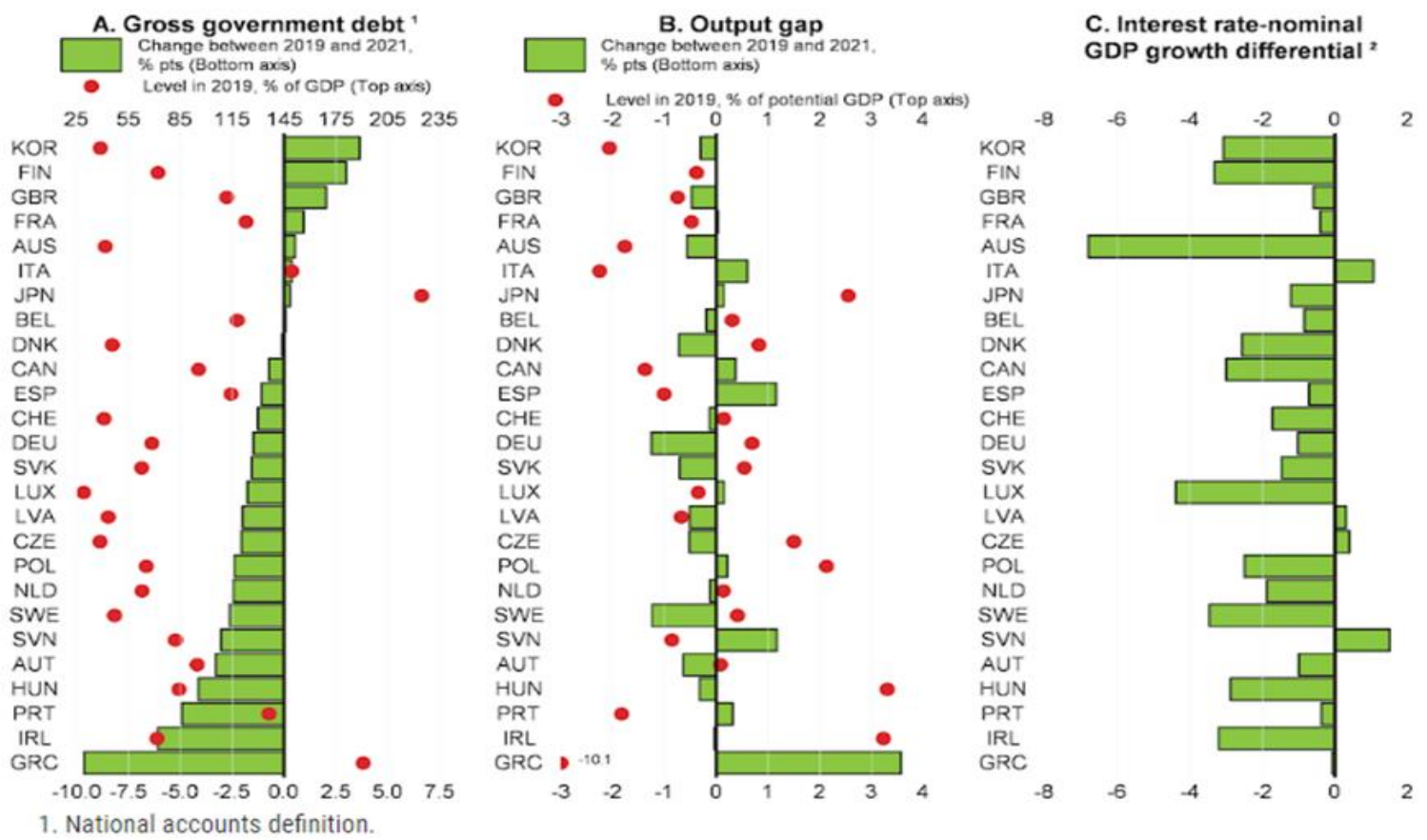

2. The average difference between the effective interest rate paid on net debt $(r)$ and nominal GDP growth $(g)$ for $2016-21$ (the so-called $\mathrm{r}-\mathrm{g}$ ). $\mathrm{r}$ is the weighted difference between the implied interest rate paid on government financial liabilities and the implied interest rate earned on government financial assets, where the weights are the share of financial liabilities and assets in net debt, respectively.

Source: OECD, Selected Indicators of Possible Changes in The Fiscal Stance https://www.oecd-ilibrary.org/sites/9b89401ben/1/2/1/index.html?itemId=/content/publication/9b89401b-en\&_csp_=dfa9d861509505eac6168a6630ad633f\&itemIGO=oecd \&itemContentType=book (Accessed March 03.2021).

Figure 1. The Appearance of Changes Influence Related to Fiscal Values on Investment Dynamics (2016-2020) 
As seen in Figure 1, it appears that there were significant variations in the public debt of OECD countries after 2012. As the OECD average, the ratio of government public debt to GDP is different and often decreases. Undoubtedly, this situation sets a trend that positively affects investments, but it is observed that the rate of interest rates is also in a decreasing trend in the same period. However, in many OECD countries, there are no significant deviations in production output [23]. It can be said that, as the OECD average, it does not significantly affect the amount of output, even though it is seen that there are increases in public debt in only a few OECD countries. On the other hand, in terms of production deficit, it appears that the most important investment deviation based on production-investment deficits due to investments is in Greece [24]. Regarding investments, it appears that production deficits related to investments generally tend to decrease. In the period after 2010, it appears that there is a severe decrease in the interest rates, which reduces investment costs, and this phenomenon indirectly reduces the tax burden on investments. It is possible to interpret this downward trend in interest rates from two structural perspectives [25]. The first is that the fall in interest rates has emerged due to a positive trend in the level of economic development of countries. The second is that as the subject of public policies related to the fall action to encourage investments with the effect that has decreased in interest rates also result in a decrease in the tax burden on investments [26]. In this context, it is possible to say that the amount of investment deficit does not create significant investment variability in the context of an investment-production deficit, except for a few countries.

Another reason for the change in the concept of the total tax burden in OECD countries is undoubted that countries act with tax competition regarding the globalization process in the tax competition process [27]. The tax competition phenomenon, which is an important factor determining investment variability in OECD countries, is an important practice in tax incentives, aiming to increase the investment level. It is also an important tool for providing a more effective public service. However, the informal economy differences between countries in OECD countries also pose significant problems in analyzing the tax burden. Regarding the tax capacity, the national income and the tax burden of the OECD countries' sectors constitute an effective mechanism that directly increases investments' effect. In practice, this financial mechanism refers to a process-focused in production outputs as a sectoral tax burden [28]. As the public financing requirement increases in the production process, the investment costs related to the increase in interest rates also unmissable negatively affect the investments as a tax burden. Here, the aim is to present the macro components of tax burden variations to be analyzed more clearly and understand how they affect an average investment variability on investments. The economic development differences of developing OECD countries cause some OECD countries' tax burden with low National Income to be perceived more than usual [29]. The purpose of achieving an objective tax burden at these countries' level is that the tax burden's pre-tax and post-tax situation put a typical neutral investment variability process. However, GDP, which includes the tax burden, government borrowings, and their main components, has a significant scale effect on investments and the investment variability as the OECD average after 2012 [30].

\section{The Econometric Analysis Approach and Empirical Method}

Our study aimed to examine the investment variability within the OECD's scope within the framework of three basic independent variables and in an approach, which takes into account approximately all OECD countries. The most important independent variable is undoubtedly the tax burden concept, and we have considered the average public debt under the OECD directly related to the phenomenon of the tax burden, and as the third independent variable, the average GDP variability in OECD countries. These three independent variables formed an effect mechanism on investment variability based on the OECD as the independent average variables. It has also been analyzed and made the weighted scale effect of the tax burden open to interpretation.

However, for each independent variable to be considered within the scope of a stationary sequence in the process, it took degree differences. As an empirical model, these independent variables were used with first-order differences in the Auto-Regressive Distributed Lag Models application (ARDL). It can be seen in table 1 below the semantic expansions of dependent and independent variables we use for Autoregressive Distributed Lag Models (ARDL).

Table 1. Structural Meanings of Model Components in The Econometric Model

\begin{tabular}{|c|c|}
\hline OECD_VY & $\begin{array}{c}\text { Average Tax Burden Changes } \\
\text { based on GDP in OECD }\end{array}$ \\
\hline GDP_OECD & $\begin{array}{c}\text { Average Gross Domestic Product } \\
\text { (GDP) for OECD }\end{array}$ \\
\hline OECD_GOV_DEBT_GDP & $\begin{array}{c}\text { Government Debt in OECD } \\
\text { Average Changes of as percent of } \\
\text { GDP }\end{array}$ \\
\hline OECD_INVSTM & $\begin{array}{c}\text { Average Changes in Investment } \\
\text { Rates in OECD }\end{array}$ \\
\hline
\end{tabular}

As seen in Table 1, it was aimed to analyze these variables with a time series model covering the years 1985-2019 regarding the analysis of investment variability based on the tax burden as the OECD average. In the establishment of the econometric model, the model was created as a level of change within the tax burden scope, with the presence of multi-directional variations, especially 
the level of influence of government debt. This stage was aimed to stabilize the series, and a time series model was created based on this:

$$
Y=\beta_{1}+\beta_{2} X_{2}+\beta_{3} X_{3}+\beta_{4} X_{4}+\beta n X n
$$

In this context, we can place the variables that we consider as Auto-Regressive Distributed Lag Model ARDL model to our model as average proportional values for OECD as follows:

$$
\begin{gathered}
\text { OECD_INVSTM }=\text { OECD_VY }+ \\
+ \text { OECD_GOV_DEBT_GDP + GDP_OECD }
\end{gathered}
$$

After forming our model as above, first-order differences of time series were taken to test the Steady State of time series used as dependent and independent variables, and unit root test applications of the time series differences were determined. In unit-root test applications, the Augmented Dickey-Fuller Test (ADF) test was used to perform the significance test with the probability significance values less than $0.05(<0.05)$ as a percentage, and the following model approach was used for this test. Within the Augmented Dickey-Fuller Test (ADF) framework, the significance determination of the unit-root values based on the equality values test aimed to determine the series's fixed and trend values. Then it was aimed to determine the unit root tests in the normal test configuration.

$$
\begin{aligned}
& H_{0}: \sigma u^{2}=0 \\
& H_{1}: \sigma u^{2} \neq 0
\end{aligned}
$$

(Fixed and Trend Model):

$$
\begin{gathered}
\Delta Y_{t}=\alpha+\beta t+\delta Y_{t-1}+\sum_{j=2}^{k} \delta_{j} \Delta Y_{t-j+1}+e_{t} \\
\Delta X_{t}=\alpha_{0}+\beta t+\rho X_{t-1}+\sum_{i=1}^{k} \beta_{i} \Delta X_{t-i}+\varepsilon_{t}
\end{gathered}
$$

Table 2 below shows the Unit Root values' position determined in the above equations and the probability values for the stationary-state of the sequences.

As seen in Table 2, it is seen that probability values are (0.000) on the basis of dependent and independent variables. We have stated before, it was aimed to create a meaningful model in which the first-order difference is taken to create our model, and the unit-root test table was created by taking the first-order differences from the time series. When the values of the unit root test results are compared as a whole for the components in our model, it appears that all variables collectively are in a structurally

\begin{tabular}{|c|c|c|c|c|}
\hline \multicolumn{5}{|c|}{ Series: OECD_INVSTMF (-1), OECD_VY(-1), OECD_GOV_DEBT_GDP (-1), GDP_OECD (-1) } \\
\hline \multicolumn{5}{|l|}{ Sample: 1983-2019 Date: 02/26/21 } \\
\hline \multicolumn{5}{|l|}{ Automatic selection of maximum lags } \\
\hline Method & Statistic & Prob. $* *$ & $\begin{array}{l}\text { Cross- } \\
\text { sections }\end{array}$ & Obs \\
\hline \multicolumn{5}{|c|}{ Null: Unit-Root (assumes common unit root process) } \\
\hline Levin, Lin \& Chu $t^{*}$ & -11.5548 & 0.0000 & 4 & 138 \\
\hline Im, Pesaran and Shin W-stat & -11.5891 & 0.0000 & 4 & 138 \\
\hline ADF - Fisher Chi-square & 103.742 & 0.0000 & 4 & 138 \\
\hline PP - Fisher Chi-square & 101.280 & 0.0000 & 4 & 140 \\
\hline
\end{tabular}
stationary system relationship since the probability values are "0.000". We can see the unit-root test summary results in the stationary unit process for all components in Table 3.

Table 2. Stationary Test Results Regarding the Unit-root Test

\begin{tabular}{|c|c|c|c|c|}
\hline Variable & Coefficient & Std. Error & t-statistic & Prob. \\
\hline (OECD_VY) Df(-1) & -0.952089 & 0.170935 & -5.569888 & 0.0000 \\
\hline (GDP_OECD) Df(-1) & -1.774053 & 0.265707 & -6.676718 & 0.0000 \\
\hline (OECD_GOV_DEBT_GDP) Df(-1) & -1.315804 & 0.192676 & -6.829089 & 0.0000 \\
\hline (OECD_INVSTM) Df(-1) & -1.278362 & 0.165245 & -7.736182 & 0.0000 \\
\hline
\end{tabular}

Table 3. Group unit root test Summary Values of All Model Variables 


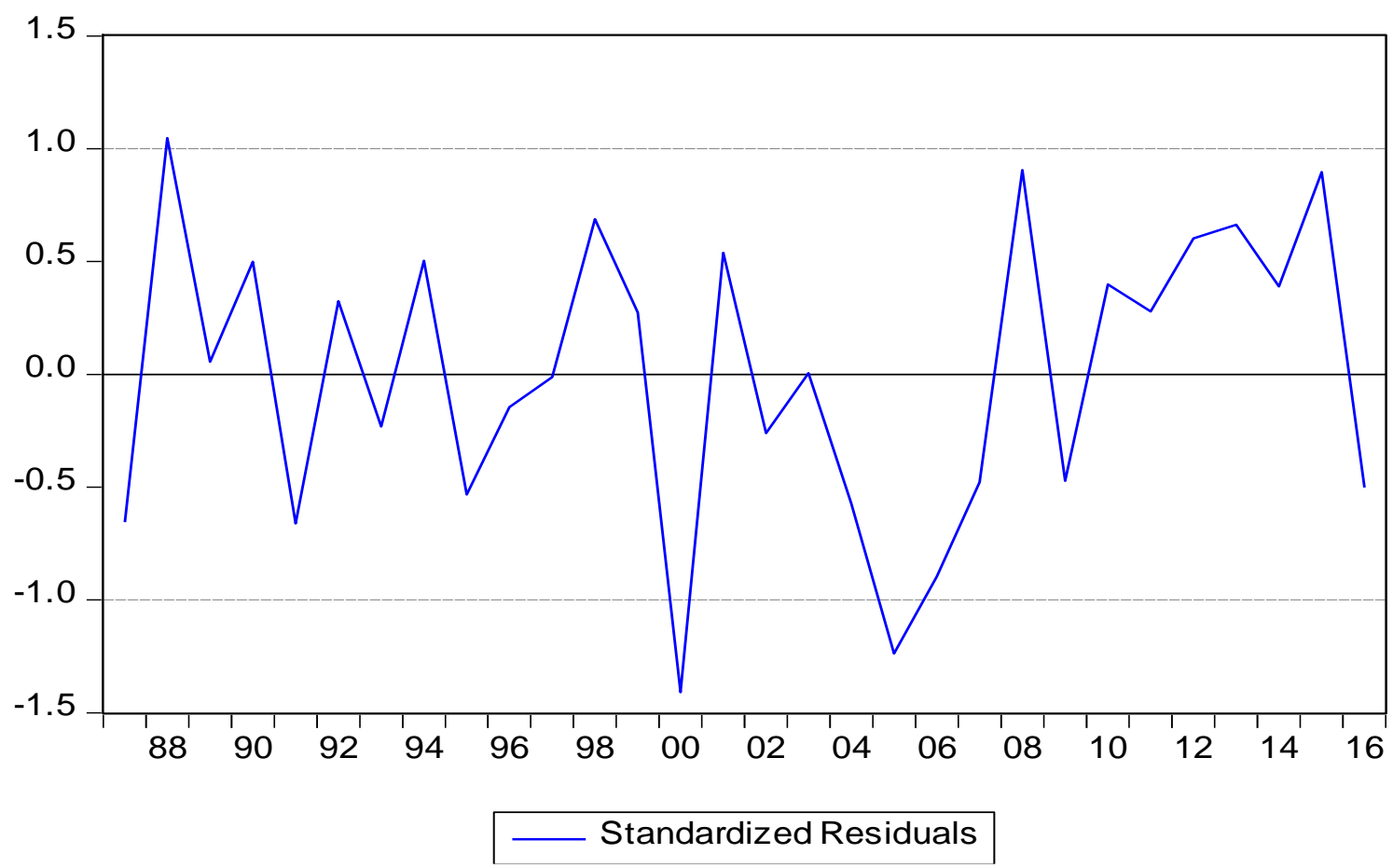

Figure 2. The Standardized Residual Graph in Stationary-State

This structure, in which all four components are stationary as a series, constitutes an important stage in the meaningful interpretation of the OECD investment sequence, which is the dependent variable. And then, it was aimed to form a model in which all the sequences are also taken in other differences according to the ARDL test after the stationary of the sequences is achieved. Figure 2 shows The Standardized Residual Graph in the stationary-state position distribution within the scope of ARDL model.

Within the framework of the ARDL model, the following difference table was created to ensure the stationary of the unit root tests, the three differences were taken in the creation of the model within the framework of the ARDL model, and the determinations regarding the following model were made within this framework. Therefore, the creation of the model, firstly, after testing the unit root tests, different sequences or the situation that disrupts the stationary has been eliminated in the model below.

\section{Estimation Equation:}

$$
\begin{gathered}
\text { OECD_INVSTM }=+ \text { C }(1) * \text { OECD_INVSTM }(-1)+ \\
\text { C }(2) * \text { OECD_INVSTM }(-2) \\
+ \text { C }(3) * \text { OECD_INVSTM }(-3)+\mathrm{C}(4) * \text { OECD_VY + } \\
\text { C }(5) * \text { OECD_VY }(-1)
\end{gathered}
$$

$$
\begin{aligned}
& +\mathrm{C}(6) * \mathrm{OECD} \_\mathrm{VY}(-2)+\mathrm{C}(7) * \mathrm{OECD} \_\mathrm{VY}(-3)+ \\
& \text { C }(8) * \text { OECD_VY }(-4) \\
& +\mathrm{C}(9) * \text { OECD_GOV_DEBT_GDP + } \\
& \text { C (10)*OECD_GOV_DEBT_GDP(-1) } \\
& +\mathrm{C}(11) * \text { OECD_GOV_DEBT_GDP(-2) + } \\
& \text { C(12)*OECD_GOV_DEBT_GDP(-3) } \\
& +\mathrm{C}(13) * \mathrm{GDP} \_\mathrm{OECD}+\mathrm{C}(14) * \mathrm{GDP} \_\mathrm{OECD}(-1)+ \\
& \bar{C}(15) * \text { GDP_OECD }(-2) \\
& +\mathrm{C}(16) * \mathrm{GDP} \_\mathrm{OECD}(-3)+\mathrm{C}(17) * \mathrm{GDP} \_\mathrm{OECD}(-4)+ \\
& \mathrm{C}(18)
\end{aligned}
$$

It aimed to test our model with the correlogram distribution created after determining the stationarity of the time series you used in our model with the unit root test. It has been observed that the autocorrelation values in the correlogram distribution significance compatible with the partial correlation values. The probability values we follow in the table below are important because it expresses that it provides the correlation equation autocorrelation with probability values greater than 0.05 . In this distribution of correlation values, these values reveal meaningful probability integrity, exceptionally compatible with autocorrelation values' variability. It is possible to see our correlogram expansion and probability values of the model above in Table 4 below: 
Table 4. Correlation and probability Signification distribution values of Correlogram

\begin{tabular}{|c|c|c|c|c|c|c|}
\hline \multicolumn{7}{|c|}{ Sample: 1983 2019; Date: 02/26/21; Included observations: 37} \\
\hline Autocorrelation & Partial Correlation & & $\mathbf{A C}$ & PAC & Q-Stat & Prob \\
\hline$* *|. \quad|$ & $* *|. \quad|$ & 1 & -0.274 & -0.274 & 3.0017 & 0.083 \\
\hline$\left.\cdot\right|^{* *} \quad \mid$ & $.\left.\right|^{*} . \quad \mid$ & 2 & 0.237 & 0.175 & 5.3189 & 0.070 \\
\hline $.1 . \quad \mid$ & $.1 . \quad \mid$ & 3 & -0.045 & 0.062 & 5.4068 & 0.144 \\
\hline$.\left.\right|^{*} . \quad \mid$ &.$|. \quad|$ & 4 & 0.089 & 0.056 & 5.7493 & 0.219 \\
\hline$.\left.\right|^{*} . \quad \mid$ & $.\left.\right|^{*} . \quad \mid$ & 5 & 0.094 & 0.136 & 6.1495 & 0.292 \\
\hline 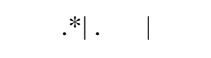 & * * I & 6 & -0.194 & -0.191 & 7.8925 & 0.246 \\
\hline$.\left.\right|^{*} \quad \mid$ &.$|. \quad|$ & 7 & 0.089 & -0.053 & 8.2740 & 0.309 \\
\hline.$* 1$ &.$|. \quad|$ & 8 & -0.112 & -0.040 & 8.8977 & 0.351 \\
\hline$.\left.\right|^{*} . \quad \mid$ & $.\left.\right|^{*} . \quad \mid$ & 9 & 0.122 & 0.081 & 9.6709 & 0.378 \\
\hline.$|. \quad|$ & $.\left.\right|^{*} . \quad \mid$ & 10 & -0.032 & 0.079 & 9.7254 & 0.465 \\
\hline.$|. \quad|$ &.$|. \quad|$ & 11 & -0.028 & -0.025 & 9.7693 & 0.551 \\
\hline * * I. I & 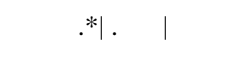 & 12 & -0.096 & -0.180 & 10.301 & 0.590 \\
\hline 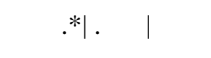 & * * | & 13 & -0.067 & -0.148 & 10.569 & 0.647 \\
\hline$.\left.\right|^{*} . \quad \mid$ & $.\left.\right|^{*} . \quad \mid$ & 14 & 0.132 & 0.126 & 11.659 & 0.634 \\
\hline$*|. \quad|$ &.$|. \quad|$ & 15 & -0.192 & -0.048 & 14.068 & 0.520 \\
\hline $.1 . \quad 1$ & $.1 . \quad \mid$ & 16 & 0.009 & -0.062 & 14.074 & 0.593 \\
\hline
\end{tabular}

With the Cointegration Test's application to verify our model's significance, the accuracy of the time series whose stationary was provided has also been questioned with the three-stage differences taken. The other purpose of the integration test is to compare and evaluate the values of the series where the first-degree stationery is achieved and the values related to the second and third differences based on the tax burden's deviation on investments. The Cointegration test has been applied within the scope of values that differ in the validation of our model's significance, and the meaning of the found test values was questioned in terms of three-stage differences. Our model's accuracy was determined by the Tax Burden effect of the test results of the First-Order discrepancies, where the stationary of the time series was ensured in the integration test, on the investments in the model created a meaningful deviation.

\section{Empirical Findings}

Study finds that the first-degree difference of the series in the change in the tax burden on investments which is the dependent variable, had a negative effect. It is understood that it presents a meaningful effect mechanism as a negative effect scale as the first-order difference in which stability is achieved. In other words, it is seen that the average tax burden, which is different from the 1st degree, increased by 1 unit within the scope of OECD countries, and it negatively affects as impact scale of "-0.917174" on investments as the average of OECD countries. The OECD average of the burden due to the changes in the effect level increases by 1 unit in a process. When the government debt scale increase by 1 unit. It is understood that the effect of government debt on investments is approximately "-0.507547" with a negative unit scale effect. While the OECD average National Income increases by 1 unit and its effect on investments affect the unit scale value, which is negative about 5\%. According to our findings, it can be said that the amount of R-squared corresponds to a ratio of approximately "0.776749" and that the independent variables in our model form a significant mechanism of influence on investments as the OECD average. Again, when evaluated in terms of probability values, almost all of the probability values being less than 5 per cent increased the significance in the model's calculations with a significant sequence. Significant findings regarding the series, which have stabilized the medium-term burden of OECD investments, can be clearly seen in Table 5 below: 
Table 5. Mutual Effect Values of Model Variables and The Significance Scale of the Model

\begin{tabular}{|c|c|c|c|c|}
\hline \multicolumn{5}{|c|}{ Dependent Variable: OECD_INVSTMFARK } \\
\hline \multicolumn{5}{|c|}{ Method: ARDL } \\
\hline \multirow{2}{*}{\multicolumn{5}{|c|}{$\begin{array}{c}\text { Sample (adjusted): } 1983-2019 \text { Date: } 02 / 25 / 21 \\
\text { Model selection method: Akaike info criterion (AIC) }\end{array}$}} \\
\hline \multicolumn{4}{|c|}{ Model selection method: Akaike info criterion (AIC) } & \\
\hline \multicolumn{5}{|c|}{ Dynamic regressors (4 lags, automatic): OECD_VY_FARK } \\
\hline Variable & Coefficient & Std. Error & t-Statistic & Prob.* \\
\hline OECD_INVSTM(-1) & 0.341041 & 0.219093 & 1.556607 & 0.0455 \\
\hline OECD_INVSTM(-2) & 0.398438 & 0.209979 & 1.897519 & 0.0421 \\
\hline OECD_INVSTM(-3) & 0.226768 & 0.205678 & 1.102543 & 0.2918 \\
\hline OECD_VY_ & -0.869408 & 0.742590 & -1.170778 & 0.0644 \\
\hline OECD_VY_(-1) & -0.917174 & 0.628911 & -1.458354 & 0.0204 \\
\hline OECD_VY_(-2) & 0.533517 & 0.602733 & 0.885162 & 0.0135 \\
\hline OECD_VY_(-3) & 0.286750 & 0.520011 & 0.551430 & 0.0315 \\
\hline OECD_VY_(-4) & -1.068248 & 0.564979 & -1.890776 & 0.0430 \\
\hline OECD_GOV_DEBT_GDP & 0.093038 & 0.148530 & 0.626394 & 0.0428 \\
\hline OECD_GOV_DEBT_GDP(-1) & -0.507547 & 0.159243 & -3.187247 & 0.0078 \\
\hline OECD_GOV_DEBT_GDP(-2) & 0.719394 & 0.213145 & 3.375149 & 0.0055 \\
\hline OECD_GOV_DEBT_GDP(-3) & -0.498639 & 0.177105 & -2.815502 & 0.0156 \\
\hline GDP_OECD & 0.204308 & 0.187542 & 1.089397 & 0.2974 \\
\hline GDP_OECD(-1) & -0.050702 & 0.258304 & -0.196287 & 0.0877 \\
\hline GDP_OECD(-2) & 0.385706 & 0.288230 & 1.338187 & 0.2056 \\
\hline GDP_OECD(-3) & 0.904536 & 0.333300 & 2.713882 & 0.0188 \\
\hline GDP_OECD(-4) & -0.837702 & 0.343981 & -2.435314 & 0.0314 \\
\hline $\mathrm{C}$ & 0.269111 & 0.226959 & 1.185725 & 0.0287 \\
\hline R-squared & 0.776749 & Mea & t var & 0.503453 \\
\hline F-statistic & 2.455945 & $\mathrm{Scl}$ & ion & 3.807057 \\
\hline Prob(F-statistic) & 0.059315 & Dur & stat & 2.043640 \\
\hline
\end{tabular}

As seen in Table 5 above, it also appears that the fourth difference of the independent variables in our model is taken. It can be said that the fourth-degree difference has a negative harmonious effect on the average investment scale values. However, it appears that the most meaningful approach in the OECD average has emerged with a negative effect on investments in terms of tax burden differences that express common and long-term. The fact that the fourth-degree difference of the OECD average Gross Domestic Product ratio is also high can be interpreted as a significant negative effect on investments in the long run. It is seen that the divergence effect on the National Income in the long-run has a negative effect on the investments of approximately "-0.837702" per-unit amount. On the other hand, a negative effect of medium and long-term government debt as "-0.498639" implies an approach compatible with the short and medium-term and cyclical tax burden changes. Besides, considering the series differences related to independent variables of our model, which we established in Table 7, we can show the effect values in our model:

OECD_INVSTMFARK $=+$ $0.341041303019 *$ OECD_INVSTM $(-1)+$ $0.398438258022 *$ OECD_INVSTM(-2) $+0.226768321069 *$ OECD_INVSTM $(-3)$ -

$$
\begin{gathered}
0.869408415489 * \text { OECD_VY } \\
-0.91717445878 * \text { OECD_VY(-1) + } \\
0.533516527468 * \text { OECD_VY(-2) } \\
+0.286749543592 * \text { OECD_VY(-3) - } \\
1.0682483427 * \text { OECD_VY }(-4) \\
+0.0930383533182 * \text { OECD_GOV_DEBT_GDP } \\
-0.507547122664 * \text { OECD_GOV_DEBT_GDP }(-1) \\
+0.719394490721 * \text { OECD_GOV_DEBT_GDP(-2) } \\
-0.498638586435 * \text { OECD_GOV_DEBT_GDP }(-3) \\
+0.204307631211 * \text { GDP_OECD - } \\
0.0507015181236 * \text { GDP_OECD(-1) } \\
+0.385706176667 * \text { GDP_OECD(-2) + } \\
0.904535862877 * \text { GDP_OECD }(-3) \\
-0.83770192364 * \text { GDP_OECD(-4) + 0.26911060462 }
\end{gathered}
$$

As an econometric finding, we can present the maximum and minimum effect values of our model's independent variables on the average investment variability in the OECD and the standard deviations for the average given values. In Table 6 below, the tax burden effect in the equation is interpreted as the component with the highest impact value among the independent components: 
Table 6. Boundary Effect Values of Independent Components and Its cumulative Standard Deviations

\begin{tabular}{|c|c|c|c|c|}
\hline & OECD_INVST (Df-1) & $\begin{array}{c}\text { OECD_VY } \\
(\mathbf{D f}-\mathbf{1})\end{array}$ & $\begin{array}{c}\text { OECD_GOV_DEBT_GD } \\
\text { P (Df-1) }\end{array}$ & $\begin{array}{c}\text { GDP_OECD } \\
\text { (Df-1) }\end{array}$ \\
\hline Mean & 0.606892 & 0.105714 & -0.113889 & -0.008316 \\
\hline Median & 0.600000 & 0.100000 & -0.150000 & 0.020000 \\
\hline Maximum & 5.200000 & 1.200000 & 7.400000 & 6.100000 \\
\hline Minimum & -4.000000 & -1.000000 & -9.500000 & -3.400000 \\
\hline Std. Dev. & 1.608468 & 0.442548 & 2.386169 & 1.321474 \\
\hline Skewness & 0.111629 & -0.040682 & -0.765137 & 2.143703 \\
\hline Kurtosis & 4.745814 & 3.697620 & 10.22002 & 14.62425 \\
\hline & & & & 236.6538 \\
\hline Jarque-Bera & 4.775637 & 0.719386 & 81.70559 & 0.000000 \\
\hline Probability & 0.091830 & 0.697890 & 0.000000 & \\
\hline & & & & -0.307700 \\
\hline Sum & 22.45500 & 3.700000 & 199.2831 & 62.86660 \\
\hline Sum Sq. Dev. & 93.13810 & 6.658857 & & 36 \\
\hline
\end{tabular}

The standard deviation regarding the tax burden is at the lowest level, which indicates that the tax burden has a more significant effect than the other components. The maximum positive impact level of the tax burden and the level of impact on investments revealed the scale of "1,200" units of maximum positive impact against the 1 unit of the increased tax burden. However, this effect is a short-term effect. The effect of the same tax burden on the average investments in OECD is interpreted to create a minimum deviation value of "-1.00", as seen in table 7 . Deviation values of the other components are in different scales but are not compatible with the probability values associated with the significance level.

\section{Conclusions}

It is understood that the effect of the tax burden on determining investment limits in OECD countries is an essential issue of OECD and a significant phenomenon in affecting the investment volume at the macro level. Although OECD member countries have different tax burdens on different economic development levels -that it is a critical handicap- it appears that analyzing this phenomenon in a structure where increases in average investment limits are targeted reveals a significant value. Although the differences in the development level of the countries reveal some significant contradictions in the process, it appears that the changes in tax burden cause significant changes in this process. For this reason, in the model we created, we included the three components that are most affected by the average investment concern values in the OECD as independent variables in our model. It appears that a weighted effect, as the correlation effect of the average tax burden, on average investments in OECD countries appears. This effect also reveals a structure in which the average government debt we use in our model and the Gross Domestic Product as an average of OECD countries are also effective. When this situation has been considered a tax burden, it is understood that guidance in the minimum and maximum tax burden values may have a negative effect close to a one-to-one level, especially on the average investments in the OECD.

However, considering this effect as long-term and short-term constitutes an important justification for our findings' more meaningful interpretation. Although the tax burden effect has a significant positive effect, especially in the short term, it is understood that it is inevitable for the tax burden to affect the medium and long term negatively. Our empirical findings reveal that average investments in the OECD are affected more than a unit value. Significant deviating effects in the short and medium run differ and over the increased average tax burden as a unit-value, especially in the long run. However, it is also meaningful that countries whose National Income levels have shrunk have a significant contraction effect on investments in the long run. In addition, we found that government debt has a negative impact on long-term investments on average OECD investments. The most significant finding here is that the short-term effects of increases in tax burden are positive with a small-scale value. This is because the increased tax burden cost is covered by the increased in the production process and reflected by the price level mechanism. However, the existence of negative effects of the tax burden in the medium and long term is essential because this phenomenon has provided a meaningful interpretation framework that confirms our findings with the divergence effect on average investments and the 
increases in the probability of the differences.

\section{REFERENCES}

[1] Waldow, P. "New Financial Instruments for Global Challenges: A Tobin Tax To Tame Hot Money and Boost Development", Financing, gate/No. 1-2001, pp. 9-11, 2001. URL: https://www2.weed-online.org/ffd/pdf/FinancingGat e_PWO.pdf.

[2] Bosdriesz, J. R., Witvliet, M. I., Visscher, T. \& Kunst, A. E. "The Influence of The Macro-Environment on Physical Activity: A Multilevel Analysis of 38 Countries Worldwide", International Journal of Behavioural Nutrition and Physical Activity 2012, Vol. 9, No. 110, pp. 1-13, 2021. DOI: 10.1186/1479-5868-9-110.

[3] Wagdi, O. \& Tarek, Y. (2019), "The Impact of Financial Risk on Systematic Risks: International Evidence", Journal of Applied Finance \& Banking, Vol. 9, No. 6, pp. 203-216. DOI: org/10.1111/j.1540-6261.1973.tb01772.x.

[4] Raičević, Božidar; Ignjatijević, Svetlana and Milojević, Ivan (2016), "Financial Analysis of Foreign Direct Investment on Economic Growth of Developing Countries", Economics of Agriculture, Vol. 63, No. 2, pp. 649-663. UDC: 330.322.54:502.131.

[5] Özker, A. N. "Tax Wedge Phenomenon and Its Possible Analytical Impacts on the Investments in OECD", Universal Journal of Accounting and Finance, Vol. 8, No. 2, pp. 41-53, 2020. DOI: 10.13189/ujaf.2020.080202.

[6] Ivanovic, Z. Bogdan, S. \& Baresa, S. "Impact of Foreign Direct Investments on Croatian Financial Growth", UTMS Journal of Economics, Vol. 5, No. 2, pp. 141-150, 2014. URL: https://ideas.repec.org/a/ris/utmsje/0107.html

[7] Santiso, J. Sovereign Development Funds: Key Financial Actors of The Shifting Wealth of Nations, OECD Emerging Markets Network Working Paper-October 2008, Paris: OECD Publishing, 2008.

[8] OECD. "Tax Effects on Foreign Direct Investment", in Policy Brief-February 2008, Paris: OECD Publishing, 2008.

[9] Turner, D. \& Spinelli, F. "Interest-Rate-Growth Differentials and Government Debt Dynamics", OECD Journal: Economic Studies, Vol. 2012/1., pp. 103-122, 2013. DOI: 10.1787/eco_studies-2012-5k912k0zkhf8.

[10] Gale, W. G. \& Samwick, A. A. "Effects of Income Tax Changes on Economic Growth", Economic Studies, Washington D.C.: The Brookings Institution, September 2014, pp. 1-15, 2014. DOI: 10.1093/acprof:oso/978019061 9725.003.0002.

[11] OECD. Tax Effects on Foreign Direct Investment, Policy Brief-February 2008, Paris: OECD Publishing, 2008.

[12] Torres, C. Taxes and Investment in Skills, OECD Taxation Working Papers No. 13, Paris: OECD Publishing, 2012.

[13] Alves, J. "The Impact of Tax Structure on Investment: An
Empirical Assessment for OECD Countries", Public Sector Economics, Vol. 43, No. 3, pp. 291-309, 2019. URL: https://doi.org/10.3326/pse.43.3.4.

[14] Enache, C. A. Comparison of the Tax Burden on Labor in the OECD, Fiscal Fact No. 710, May 2020, Washington D.C.: Tax Foundation, 2020.

[15] OECD. "Tax Policy", in Policy Framework for Investment A Review of Good Practices, Paris: OECD Publishing, pp. 103-123, 2006.

[16] OECD. OECD Economic Surveys-Turkey, OECD Overview-2018, Paris: OECD Publishing, July 2018.

[17] OECD. "Lifting Investment for Higher Sustainable Growth", in OECD Economic Outlook, Vol. 2015/1, Paris: OECD Publishing, 2015.

[18] OECD. FDI Qualities Indicators Measuring The Sustainable Development Impacts of Investment, Paris: OECD Publishing, October 2019.

[19] OECD. Tax Effects on Foreign Direct Investment - No. 17 Recent Evidence and Policy Analysis, Paris: OECD Publishing, 2007.

[20] European Commission. Guide to Cost-Benefit Analysis of Investment Projects Economic appraisal tool for Cohesion Policy 2014-2020, Brussels: European Commission Directorate-General for Regional and Urban Policy, December 2014.

[21] OECD. OECD Economic Surveys: Korea, OECD Overview-2018, Paris: OECD Publishing, June 2018.

[22] OECD, Selected Indicators of Possible Changes in The Fiscal Stance https://www.oecd-ilibrary.org/sites/9b89401 b-en/1/2/1/index.html?itemId=/content/publication/9b8940 1b-en\&_csp_=dfa9d861509505eac6168a6630ad633f\&ite mIGO=oecd\& itemContentType=book (Accessed March, 03.2021).

[23] OECD. Perspectives on Global Development 2019: Rethinking Development Strategies, OECD Overview-2018, Paris: OECD Publishing, 2018.

[24] European Commission. Enhanced Surveillance Report: Greece-November 2019, Institutional Paper 116, Brussels: European Commission Economic and Financial Affairs, November 2019.

[25] Del Negro, M., Giannone, D., Giannoni, M. P. \& Tambalotti A. Global Trends in Interest Rates, Federal Reserve Bank of New York Staff Reports No. 866, New York: Federal Reserve Bank, September 2018.

[26] OECD. Tax Incentives for Investment - A Global Perspective: Experiences in MENA and Non-MENA Countries, MENA-OECD Investment Program-June 2007, Paris: OECD Publishing, 2007.

[27] OECD. Tax Co-Operation for Development - Progress Report, Paris: OECD Publishing, 2020.

[28] OECD. Tax Policy Assessment and Design in Support of Direct Investment: A Study of Countries in South East Europe, Stability Pact: South East Europe Compact for Reform, Investment, Integrity and Growth Paris: OECD Directorate for Financial, Fiscal and Enterprise Affairs and 
The OECD Tax Centre for Tax Policy and Administration, April 2003.

[29] OECD. Corporate Tax Statistics, $2^{\text {nd }}$ Ed. Paris: OECD Publishing, 2020.
[30] Hanappi, T. "Corporate Effective Tax Rates: Model Description and Results from 36 OECD and Non-OECD Countries", OECD Taxation Working Papers, No. 38, Paris: OECD Publishing, 2018. 